\title{
Association between lifestyle and hypertriglyceridemic waist phenotype in the
}

\section{PREDIMED-Plus study}

José Carlos Fernández-García^^${ }^{\wedge 1,2}$, Araceli Muñoz-Garach^1,2, Miguel Ángel MartínezGonzález $^{2,3,4}$, Jordi Salas-Salvado ${ }^{2,5,6,7}$, Dolores Corella ${ }^{2,8}$, Álvaro Hernáez ${ }^{2,9,10}$, Dora Romaguera $^{2,11}$, Jesús Vioque ${ }^{12,13}$, Ángel M. Alonso-Gómez ${ }^{2,14,15}$, Julia Wärnberg ${ }^{2,16}$, J. Alfredo Martínez ${ }^{2,17,18}$, Luís Serra-Majem ${ }^{2,19}$, Ramón Estruch ${ }^{2,9,20}$, José Lapetra ${ }^{2,21}$, Xavier Pintó ${ }^{2,20,22}$, Josep A. Tur ${ }^{2,23}$, Antonio Garcia-Rios ${ }^{2,24}$, Laura García Molina ${ }^{12,25}$, José Juan Gaforio ${ }^{12,26}$, Pilar Matía-Martín ${ }^{27}$, Lidia Daimiel ${ }^{28}$, Vicente Martín Sánchez ${ }^{12,29}$, Josep Vidal ${ }^{30,31}$, Lucia Prieto ${ }^{32}$, Emilio Ros ${ }^{2,33}$, Nuria Goñi ${ }^{2,3}$, Nancy Babio $^{2,5,6,7}$, Carolina Ortega-Azorin ${ }^{2,8}$, Olga Castañer ${ }^{2,34}$, Jadwiga Konieczna ${ }^{2,11}$, Leyre Notario Barandiaran ${ }^{12,13}$, Jessica Vaquero-Luna ${ }^{2,14}$, Juan Carlos Benavente-Marín ${ }^{2,16}$, M Angeles Zulet ${ }^{2,17}$, Almudena Sanchez-Villegas ${ }^{2,19}$, Emilio Sacanella ${ }^{2,9,20}$, Ricardo Gómez Huelgas ${ }^{2,35}$, Leticia Miró-Moriano ${ }^{2,21}$, Mariano Gimenez-Gracia ${ }^{2,22}$, Alicia Julibert $^{2,11,23}$, Cristina Razquin ${ }^{2,3,4}$, Josep Basora ${ }^{5,7}$, Olga Portolés ${ }^{2,8}$, Albert Goday ${ }^{20,34}$, Aina M Galmés-Panadés ${ }^{2,11}$, Carmen M. López-García ${ }^{36}$, Anai Moreno-Rodriguez ${ }^{2,14}$, Estefanía Toledo ${ }^{2,3,4}$, Andrés Díaz-López ${ }^{2,5,6,7}$, Montserrat Fitó ${ }^{2,34}$, Francisco J Tinahones $^{1,2^{\star}}$, M Rosa Bernal-López ${ }^{2,35^{*}}$, PREDIMED-Plus Investigators.

\footnotetext{
${ }^{1}$ Department of Endocrinology and Nutrition, Virgen de la Victoria University Hospital, Malaga University. Instituto de Investigación Biomédica de Malaga (IBIMA), Malaga, Spain.

${ }^{2}$ Centro de Investigación Biomédica en Red Fisiopatología de la Obesidad y la Nutrición (CIBEROBN), Institute of Health Carlos III, Madrid, Spain

${ }^{3}$ University of Navarra, Department of Preventive Medicine and Public Health, IDISNA, Pamplona, Spain

${ }^{4}$ Department of Nutrition, Harvard T.H. Chan School of Public Health, Boston, MA, USA

${ }^{5}$ Universitat Rovira i Virgili, Departament de Bioquímica i Biotecnologia, Unitat de Nutrició, Reus, Spain

${ }^{6}$ University Hospital of Sant Joan de Reus, Nutrition Unit, Reus, Spain

${ }^{7}$ Institut d'Investigació Sanitària Pere Virgili (IISPV), Reus, Spain

${ }^{8}$ Department of Preventive Medicine, University of Valencia, Valencia, Spain

${ }^{9}$ Department of Internal Medicine, Institut d'Investigacions Biomèdiques August Pi Sunyer (IDIBAPS), Hospital Clinic, Barcelona, Spain

${ }^{10}$ Blanquerna, School of Health Sciences Organization Universitat Ramon Llull, Barcelona, Spain

${ }^{11}$ Health Research Institute of the Balearic Islands (IdISBa), Palma de Mallorca, Spain.

${ }^{12}$ CIBER de Epidemiología y Salud Pública (CIBERESP), Instituto de Salud Carlos III, Madrid, Spain

${ }^{13}$ Miguel Hernandez University, ISABIAL-FISABIO, Alicante, Spain

${ }^{14}$ Department of Cardiology, Organización Sanitaria Integrada (OSI) ARABA, University Hospital Araba, Vitoria-Gasteiz, Spain

${ }^{15}$ University of the Basque Country UPV/EHU, Vitoria-Gasteiz, Spain

${ }^{16}$ Department of Nursing, School of Health Sciences, University of Málaga-Instituto de Investigación Biomédica de Malaga (IBIMA), Málaga, Spain

${ }^{17}$ Department of Nutrition, Food Sciences, and Physiology, Center for Nutrition Research, University of Navarra, Pamplona, Spain.

${ }^{18}$ Cardiometabolic Nutrition Group, IMDEA Food, CEI UAM + CSIC, Madrid, Spain.
} 
${ }^{19}$ Nutrition Research Group, Research Institute of Biomedical and Health Sciences (IUIBS), University of Las Palmas de Gran Canaria, Las Palmas de Gran Canaria, Spain.

${ }^{20}$ Universidad de Barcelona, Barcelona, Spain

${ }^{21}$ Department of Family Medicine, Research Unit, Distrito Sanitario Atención Primaria Sevilla, Sevilla, Spain

${ }^{22}$ Lipids and Vascular Risk Unit, Internal Medicine, Hospital Universitario de Bellvitge-IDIBELL, Hospitalet de Llobregat. Barcelona, Spain

${ }^{23}$ Research Group on Community Nutrition \& Oxidative Stress, University of Balearic Islands, 07122 Palma de Mallorca, Spain

${ }^{24}$ Department of Internal Medicine, Maimonides Biomedical Research Institute of Cordoba (IMIBIC), Reina

Sofia University Hospital, University of Cordoba, Cordoba, Spain

${ }^{25}$ Department of Preventive Medicine and Public Health, University of Granada, Granada, Spain

${ }^{26}$ Division of Preventive Medicine, Faculty of Medicine, University of Jaén, Jaén, Spain

${ }^{27}$ Department of Endocrinology and Nutrition, Instituto de Investigación Sanitaria Hospital Clínico San Carlos (IdISSC), Madrid, Spain

${ }^{28}$ Nutritional Genomics and Epigenomics Group, IMDEA Food, CEI UAM + CSIC, Madrid, Spain

${ }^{29}$ Institute of Biomedicine (IBIOMED), University of León, León, Spain

${ }^{30}$ CIBER Diabetes y Enfermedades Metabólicas (CIBERDEM), Instituto de Salud Carlos III (ISCIII), Madrid, Spain

${ }^{31}$ Department of Endocrinology, Institut d’ Investigacions Biomédiques August Pi Sunyer (IDIBAPS), Hospital Clinic, University of Barcelona, Barcelona, Spain.

${ }^{32}$ Department of Endocrinology, Fundación Jiménez-Díaz, Madrid, Spain

${ }^{33}$ Lipid Clinic, Department of Endocrinology and Nutrition, Institut d'Investigacions Biomèdiques August $\mathrm{Pi}$ Sunyer (IDIBAPS), Hospital Clínic, Barcelona, Spain

${ }^{34}$ Unit of Cardiovascular Risk and Nutrition, Institut Hospital del Mar de Investigaciones Médicas Municipal d’Investigació Médica (IMIM), Barcelona, Spain.

${ }^{35}$ Department of Internal Medicine, Regional University Hospital of Malaga, Instituto de Investigación Biomédica de Malaga (IBIMA), Malaga 29010, Spain

${ }^{36}$ Centro Salud Raval de Elche, Alicante, Spain

^These authors contributed equally to this work.

\section{Running Head: Hypertriglyceridemic waist and PREDIMED-Plus study}

Disclosure: The authors declare no conflict of interest

PREDIMED-Plus study is registered with ISRCT registry. http://www.isrctn.com/ ISRCTN89898870

Word count main text: 3221

Tables: 5

\section{Correspondence to:}

- Dr. M Rosa Bernal Lopez. Internal Medicine Department, Instituto de Investigación Biomédica de Málaga (IBIMA), Regional Hospital of Málaga, Avda. Hospital Civil s/n, 29009 Malaga, Spain. E-mail address: robelopajiju@yahoo.es

- Prof. Francisco J. Tinahones. Department of Endocrinology and Nutrition, Virgen de la Victoria University Hospital, Málaga University. Instituto de Investigación Biomédica de Málaga (IBIMA). Campus de Teatinos s/n. Málaga 29010, Spain. E-mail: fjtinahones@hotmail.com 


\section{Abstract}

Objective: Hypertriglyceridemic waist (HTGW) phenotype is characterized by abdominal obesity and high levels of triglycerides (TGs). We aim to evaluate HTGW phenotype prevalence, analyze associated risk factors, and examine the lifestyle of individuals with metabolic syndrome and HTGW in a cross-sectional assessment of PREDIMED-Plus trial subjects at baseline.

Methods: 6874 subjects aged 55-75 with body mass index (BMI) $\geq 27$ and $<40 \mathrm{~kg} / \mathrm{m} 2$ were included. Subjects were classified by presence (HTGW+) or absence (HTGW-) of HTGW (waist circumference: men $\geq 102 \mathrm{~cm}$, women $\geq 88 \mathrm{~cm}$; fasting plasma TGs $\geq 150$ $\mathrm{mg} / \mathrm{dL}$ ). Analytical parameters and lifestyle (energy intake and expenditure) were analyzed.

Results: $38.2 \%$ were HTGW+. HTGW+ subjects tended to be younger, more obese, sedentary, and tobacco users. They had higher peripheral glucose, total, and LDL cholesterol levels; lower HDL cholesterol levels; and increased prevalence of type 2 diabetes (T2DM). Mediterranean diet (MedDiet) adherence and physical activity (PA) were greater in HTGW- patients. Age, BMI, tobacco use, total energy expenditure, hypertension, T2DM, and MedDiet adherence were associated with HTGW+.

Conclusion: HTGW is a highly prevalent phenotype in our population. It is associated with younger age, higher BMI, tobacco use, and decreased MedDiet adherence. HTGW- subjects were more physically active with greater total PA and fewer had hypertension.

Keywords: Clinical Trials; Abdominal obesity; Hypertriglyceridemia; Life Styles. 


\section{What is already known about this subject?}

- Hypertriglyceridemic waist (HTGW) is an alternative concept to metabolic syndrome.

- HTGW is a phenotype of cardiometabolic risk prevalent in the adult population

- HTGW may be an alternative to the metabolic syndrome to detect the population at risk for Type 2 Diabetes Mellitus (T2DM) and cardiovascular disease (CVD), especially in young people who have no criteria for the metabolic syndrome.

\section{What does this study add?}

- This study evaluates the relationship between metabolic risk factors and HTGW phenotype in elderly at high cardiovascular risk.

- Our results showed that the prevalence of HTGW+ phenotype is high and is closely associated with a sedentary lifestyle, an important risk factor in the development of obesity-related metabolic pathologies. 


\section{Introduction}

Hypertriglyceridemic waist (HTGW) is an alternative concept to metabolic syndrome (MetS) as a simple and reliable indicator of cardiovascular and metabolic risk in subjects with visceral obesity [1]. The HTGW phenotype is characterized by the simultaneous presence of increased waist circumference (WC) and high levels of triglycerides (TGs); it is a better predictor of cardiovascular risk than each component separately $[2,3]$.

Few studies have analyzed the presence of the HTGW phenotype in the adult population and cut-off points for defining it have yet to be determined [4]. The HTGW phenotype has been used to identify individuals who are susceptible to being at greater risk of cardiometabolic disorders such as high body mass index (BMI), elevated Creactive protein (CRP), increased total cholesterol, decreased high-density lipoproteins (HDLC), and elevated low-density lipoproteins (LDLC) [5].

Obesity and unhealthy lifestyles (physical inactivity and a high calorie diet) are modifiable factors related to the development and worsening of HTGW [6]. The Mediterranean diet (MedDiet), characterized by the abundant consumption of olive oil, fruit, vegetables, legumes, whole-grain cereals, and nuts; moderate intake of red wine with meals, fish, seafood, fermented dairy products, poultry, and eggs; and low consumption of red and processed meats, dairy, and sweets [7] is a protective factor against cardiovascular disease, obesity, dyslipidemia, and T2DM [8]; reduces WC [9]; and decreases the incidence of major cardiovascular events [10-12]. Furthermore, programmed aerobic physical activity (PA), done regularly over time and individualized in type and intensity, also offers cardiometabolic benefits $[13,14]$

However, despite the marked association between metabolic risk factors and HTGW phenotype, few studies have evaluated this relationship in elderly at high cardiovascular risk. Thus, this study aimed to carry out a cross-sectional analysis to examine the presence of HTGW phenotype in our cohort at baseline conditions and prior to randomization. We analyze risk factors associated with this phenotype, and evaluate the lifestyle of the individuals with the HTGW phenotype in the PREDIMED-Plus Study.

\section{Subjects and Methods}

This study is a cross-sectional analysis of baseline data from the PREDIMEDPlus study. The PREDIMED-Plus study is a 6-year multicenter, randomized, parallel-group, primary cardiovascular prevention clinical trial conducted in Spain. Participants were randomized to receive either MedDiet and general 
recommendations on diet and exercise or more in-depth advice on MedDiet and support from a nutritionist along with PA. MedDiet started when subjects signed the informed consent form. A more detailed description of the PREDIMED-Plus study is available at http://PREDIMEDplus.com/ [15]. This study is registered with the International Standard Randomised Controlled Trial (ISRCT) registry. http://www. isrctn.com/ ISRCTN89898870. Registration date: 24 July 2014.

Patients were recruited and randomized in 23 centers in Spanish universities, hospitals, and research institutes from October 2013 to December 2016. Inclusion criteria were males aged 55-75 years and women aged 60-75 years with overweight/ obesity (BMI $\geq 27$ and $<40 \mathrm{~kg} / \mathrm{m}^{2}$ ) who met at least three MetS criteria, defined according to the updated harmonized criteria of the International Diabetes Federation, the American Heart Association, and the National Heart, Lung and Blood Institute [16]. All patients provided written informed consent. The study protocol and procedures were approved according to the ethical standards of the Declaration of Helsinki in all the participating centers by institutional ethical committees.

Exclusion criteria included previous cardiovascular disease (acute myocardial infarction or stroke); cancer or a history of cancer in the last 5 years (with the exception of non-melanoma skin cancer); inability to follow the recommended diet or inability to perform PA; low probability of changing eating habits; inability to come to the scheduled visits for the intervention; being immobile, pregnant, or hospitalized at the time of the study; and having a severe psychiatric disorder, alcohol use disorder, or drug addiction.

In this study, the population was classified according to presence or absence of HTGW (HTGW+/HTGW-), diagnosed using anthropometric criteria for the European population and biochemical parameter level. These criteria include a WC for men $\geq 102$ $\mathrm{cm}$ and for women $\geq 88 \mathrm{~cm}$ [17] as well as fasting plasma TGs $\geq 1.71 \mathrm{mmol} / \mathrm{L}$ ( $\geq 150 \mathrm{mg} /$ $\mathrm{dL}$ ) $[18,19]$. Measurements of weight, height, BMI, WC (at the mid-point between the anterosuperior iliac crest and the last costal arch, parallel to the ground and upon exhalation), and blood pressure (mean of three measurements after a 5-minute rest) were carried out following the PREDIMED-Plus operations protocol by previously trained healthcare workers (doctors or nurses) in duplicate.

Blood analyses were performed after a 12-hour fast. Samples were analyzed in the laboratory of the reference hospital and biochemical measurements were obtained using routine methods. Samples from patients were immediately processed after their reception and frozen following current procedures. They were then handled by the PREDIMED-Plus common biobank of samples following standardized work protocols. 
All patients underwent a lifestyle modification consisting of a nutritional intervention (MedDiet) and PA. For the nutritional assessment, all patients filled in a validated semi-quantitative 137-item food frequency questionnaire to assess dietary habits $[20,21]$ as well as a validated 17-item questionnaire [22] to measure the degree of adherence to the MedDiet. High adherence was considered to be a result of 12-17 points, moderate adherence a result of 8-11 points, low adherence a result of 5-7 points, and very low adherence a result of $<5$ points. Finally, PA (duration and intensity) was measured using a self-reported and validated Regicor Short Physical Activity Questionnaire (RSPAQ) [23-24]. The validation study of the RSPAQ revealed high reliability (intraclass correlation coefficient for total-PA $=0.82$ ) and reasonable validity (Spearman correlation coefficient for total-PA $=0.39$ ). Sedentarism was evaluated using the Rapid Assessment of Physical Activity (RAPA) questionnaire, a 7-item questionnaire where sedentarism was defined as a score of 1-3 points [25].

\section{Statistical analysis}

The database used for this study was the complete PREDIMED-Plus database available as of June $13^{\text {th }}, 2017$ (internal code: 201706131354_PREDIMEDplus_201706-13). Quantitative variables are expressed as means and standard deviations (SD) and qualitative variables as a percentage. Student's t-test was used to compare quantitative variables and the Chi-square test and Mantel-Haenszel test for qualitative variables. In order to determine factors that were independently associated with the prevalence of HTGW, multivariate logistic regression techniques were applied using HTGW as a dependent variable and controlling for confounding variables such as age, BMI, tobacco use, sedentarism, education level, PA, adherence to MedDiet, and presence of comorbidities (T2DM or hypertension). Finally, bivariate correlations were determined using the Pearson correlation coefficient analysis.

We used the baseline study database generated in August 2017. All analyses were done with SPSS, version 22.0.

\section{Results}

Of the initial 6874 subjects included in the PREDIMED-Plus trial, $142(2.1 \%)$ did not meet the inclusion criteria for the present study. Therefore, 6732 patients were included in this study (3488 (51.8\%) men and 3244 (48.2\%) women). Mean age was $65.0 \pm 4.9$ years old, mean BMl was $32.7 \pm 3.4 \mathrm{~kg} / \mathrm{m}^{2}$, and mean WC was $108.1 \pm 9.7 \mathrm{~cm}$. The population was classified according to presence or absence of HTGW. A total of 
2574 subjects $(38.2 \%)$ met HTGW criteria. Table 1 shows the clinical and biochemical differences between HTGW+ and HTGW- subjects.

The HTGW+ group was younger $(p<0.0001)$; more obese $(p<0.0001)$; had a higher prevalence of a sedentary lifestyle $(p<0.0001)$; a higher prevalence of smoking habits $(p=0.001)$; and higher glucose $(p<0.0001)$, HbA1c $(p<0.0001)$, creatinine $(p<0.0001)$, and lipid profile levels (total cholesterol, LDLc, and TGs) combined with lower HDLc levels ( $p<0.0001$ for all) than HTGW- subjects. In addition, prevalence of T2DM was significantly higher in the HTGW+ population $(28.5 \%$ vs 26.0 ; $\mathrm{p}<0.0001$; OR 0.89 [0.80-0.99]).

Energy consumption, food intake, and adherence to MedDiet are summarized in Table 2. 90 participants (40 with HTGW+ and 50 with HTGW-) did not complete the food frequency questionnaire. No significant differences were found in energy consumption and food intake between the two groups (Table 2A). The entire study population completed the questionnaire about adherence to MedDiet. This questionnaire revealed that HTGW- participants had greater adherence to MedDiet in comparison with all participants, a finding that was statistically significant $(p<0.0001)$ (Table 2B).

Energy expenditure was associated with HTGW. As shown in Table 3, HTGW+ subjects did slightly more light exercise than HTGW- subjects, though this finding was not statistically significant. However, HTGW+ subjects did significantly less moderate and vigorous PA (-200 Met.min/week (w), respectively) and total PA (-300 Met.min/w) than HTGW- patients.

Table 4 shows the linear correlations between levels of TGs and WC with various baseline characteristics, adherence to MedDiet, and PA in $\mathrm{HTGW}+$ and HTGW- subjects. In the HTGW+ group, levels of TGs were significantly negatively correlated with age, HDLc levels, and performing vigorous PA. They were positively correlated with tobacco use; presence of T2DM; and glucose, creatinine, VLDLc, and $\mathrm{HbA} 1 \mathrm{c}$ levels. WC was negatively correlated with age; education level; total cholesterol, LDLc, and HDLc levels; MedDiet adherence and performing vigorous PA. Moreover, WC was positively correlated with BMI; tobacco use; presence of CVD and T2DM; glucose, creatinine, HbA1c, and VLDLc levels; sedentarism; and total PA. In the HTGW- group, levels of TGs were significantly negatively correlated with age, BMI, presence of CVD, education level, HDLC levels, and MedDiet adherence. They were positively correlated with tobacco use and creatinine, LDLc, and VLDLc levels. On the other hand, WC was negatively correlated with age; education level; total cholesterol, LDLc, VLDLc, and HDL levels; MedDiet adherence; performing vigorous PA; and total PA. Moreover, WC was positively 
correlated with BMI; tobacco use; presence of CVD and T2DM; glucose, $\mathrm{HbA} 1 \mathrm{c}$, and creatinine levels; and sedentarism.

According to the adjusted logistic regression model (OR), age (OR 0.98 [0.970.99]), adherence to MedDiet (OR 0.96 [0.95-0.98]), total energy expenditure (OR 0.995 [0.994-0.996]), and hypertension in treatment (OR 0.84 [0.73-0.96]) protected against presence of the HTGW phenotype (Table 5).

\section{Discussion}

Our results indicate that in the PREDIMED-Plus study, almost $40 \%$ of the population had HTGW. Patients with HTGW were slightly younger-all in their 60smore physically inactive, had lower adherence to the MedDiet, and had a higher prevalence of tobacco use. We recruited subjects with different age ranges according to whether they were male or female, according to study protocol. It is well known that among individuals without diabetes, absolute rates of CVD are higher in men than in women at all ages except for very old ages, where prevalence of stroke is higher in women than in men [26]. Therefore, we included older women in order to create groups with similar risk. These HTGW+ patients also had higher levels of glucose, total cholesterol, LDLc, and TGs and lower levels of HDLc. Furthermore, this population had a higher prevalence of T2DM. These data are in concordance with findings recently published by other authors $[\mathbf{2 7 , 2 8}]$. According to previous studies, prevalence of HTGW increases with age, reaching almost $30 \%$ in those aged 60-69 years [1]. We found an unusual negative association between HTGW+ and age. This fact could be explained to decreased adherence to the MedDiet in younger patients (<65 years). Furthermore, García Álvarez A. et al. suggested a positive association between smoking and central obesity in the Spanish population [29].

Obesity is accompanied by multiple hormonal, inflammatory and endothelial abnormalities. These abnormalities induce stimulation of several other mechanisms that contribute to hypertension and increased cardiovascular morbidity [30]. In our study, we observed that drug treatment associated with changes in diet and lifestyle protect against the presence of HTGW. This data is in concordance with a statement published in 2012 by the European Association for the Study of Obesity and the European Society of Hypertension [31], which highlighting recommendations for preventing and treating obesity and complications associated with obesity based on the rationale that weight reduction may have a beneficial effect on overall risk and may contribute to blood pressure control. 
The use of WC as a fundamental parameter for defining MetS is becoming more common as WC is correlated with high triglyceride levels. HTGW is a cardiometabolically risky phenotype that is prevalent in the adult population and is an alternative to MetS for detecting people at risk for T2DM, particularly in young individuals who do not meet MetS criteria [1].

HTGW+ prevalence was elevated in our population. Factors such as age, BMI, tobacco use, adherence to MedDiet, and total energy expenditure were associated with the presence of HTGW, according with Fagundes LC et al. [32]. In this study, the population aged $\geq 60$ years had a high prevalence of HTGW, with physical inactivity and overweight as key factors associated with this phenotype.

Lifestyle (a healthy diet and PA) is very important in preventing the causes of morbidity and mortality associated with MetS. In regards to diet, some authors have recently demonstrated that MetS [33] and T2DM [34] could be prevented by eating a healthy diet, such as the MedDiet. In our population, no significant differences were found between the different components of MedDiet and the presence/absence of HTGW. These data are in concordance with the findings of Andrade JR et al. [35]. The HTGW+ population consumed more total fat $(+8 \mathrm{~g} / \mathrm{d})$ and cholesterol $(+6 \mathrm{~g} / \mathrm{d})$, thus indicating decreased adherence to the MedDiet prior to randomization. Some strategies to reduce high levels of TGs and HTGW are to reduce excess weight and the total amount of dietary carbohydrates. In addition, it is recommended to increase PA and that saturated fatty acids (SFA) be substituted by monounsaturated fatty acids (MUFA) and polyunsaturated fatty acids (PUFA) [36]. It has been shown that the MedDiet, which is characterized by low SFA (8\%) and high MUFA (12\%), PUFA (8\%), and fiber content, promote a significant reduction in levels of TGs [10,37].

The MedDiet prevents loss of lean mass and improves metabolic parameters in the population with obesity [38]. Therefore, high adherence to the MedDiet could protect against developing HTGW since this diet could led to a greater reduction in triglyceride levels than others [39].

In regards to PA, a great majority (80.4\%) of HTGW+ in our study were obese. Coinciding with other studies [40], the presence of HTGW and abdominal fat were more prevalent in the sedentary population. Previous studies have shown that presence of HTGW can be associated with sedentarism [41]. Studies also show that higher intensity (moderate-vigorous) PA reduces abdominal fat accumulation [42] and was negatively associated with waist circumference [43]. In addition, PA has a beneficial effect on numerous metabolic and cardiovascular risk factors and reduces the risk of Type 2 Diabetes Mellitus (T2DM) and cardiovascular disease (CVD) [44]. This effect is in accordance with our results, which demonstrated that the subjects who 
performed higher intensity PA (moderate-vigorous) tended not to have HTGW. On the other hand, some studies found no differences between PA intensity and components of abdominal fat distribution, suggesting that health benefits from PA are related to an overall reduction in adipose tissue [42]. A strong association between PA (moderate or vigorous) and visceral and subcutaneous adipose tissue has been demonstrated, indicating the protective effect of PA against fat deposition in the general population with sedentary lifestyle habits [45].

According to the results of this study, we can affirm that a lifestyle based on MedDiet and regular PA prevents the appearance of HTGW in subjects with MetS. Furthermore, it also reduces the risk of developing diseases associated with obesity such as T2DM or CVD.

Our study has some limitations. This study was carried out in subjects who have MetS or T2DM, are Caucasian, are of advanced age, and who were recruited to follow the established MedDiet guidelines. Our results were taken when follow-up was started. Therefore, the results cannot be extrapolated to other populations with different pathologies, who are of different races or ages, or who have another type of energy intake. Nevertheless, the study analyzed a large sample of participants of both sexes. This lends robustness to the results obtained and as such, the public health message encouraging healthy lifestyle habits for all obese patients should continue to be emphasized as it has been demonstrated that MedDiet could be useful in preventing greater cardiovascular risk.

In conclusion, the data obtained from a sample of the Spanish adult population indicate that the prevalence of HTGW+ phenotype is high-almost $40 \%$-and is closely associated with a sedentary lifestyle, which is an important risk factor in the development of obesity-related metabolic pathologies.

\section{Acknowledgements}

We thank all PREDIMED-Plus participants and investigators. CIBEROBN, CIBERESP, and CIBERDEM are initiatives of the Instituto de Salud Carlos III (ISCIII), Madrid, Spain. The Hojiblanca (Lucena, Spain) and Patrimonio Comunal Olivarero (Madrid, Spain) food companies donated extra-virgin olive oil. The Almond Board of California (Modesto, CA), American Pistachio Growers (Fresno, CA), and

Paramount Farms (Wonderful Company, LLC, Los Angeles, CA) donated nuts. The authors also thank the PREDIMED-Plus Biobank Network, part of the ISCIII National Biobank Platform, for storing and managing the PREDIMED-Plus biological samples. Thanks to Malaga 
Hospital-IBIMA Biobank, member of the Andalusian Public Health System Biobank, part of the National Biobank Platform (project PT13/0010/0006). Thanks to Claire Alexandra Conrad for her help with the final English-language version.

Funding. Funding. The PREDIMED-Plus trial was supported by grants from the Instituto de Salud Carlos III, cofinanced by the Fondo Europeo de Desarrollo RegionalFEDER including the following projects: PI13/00673, PI13/00492, PI13/00272, Pl13/01123, Pl13/00462, Pl13/00233, Pl13/02184, Pl13/00728, Pl13/01090, Pl13/01056, PI14/01722, PI14/00636, PI14/00618, PI14/00696, PI14/01206, Pl14/01919, Pl14/00853, Pl14/01374, Pl16/00473, PI16/00662, PI16/01873, PI16/01094, PI16/00501, Pl16/00533, PI16/00381, PI16/00366, PI16/01522, Pl16/01120, PI17/00764, PI17/01183, PI17/00855, Pl17/01347, Pl17/00525, PI17/01827, PI17/00532, PI17/00215, PI17/01441, PI17/00508, PI17/01732, and PI17/00926; the Cohorte PREDIMED-PLUS grant; the European Research Council (Advanced Research Grant 2014-2019, 340918 granted to MAM-G); the Recercaixa grant (2013ACUP00194); grants from Consejeria de Salud de la Junta de Andalucia (PI0458/2013, PS0358/2016, PI0092/2017, PI0096/2017 and PI0137/2018); a grant from the Generalitat Valenciana (PROMETEO/2017/017); a SEMERGEN grant, and funds from the European Regional Development Fund (CB06/03). M Rosa BernalLopez was supported by "Miguel Servet Type I" program (CP15/00028) from the ISCIIIMadrid (Spain), cofinanced by the Fondo Europeo de Desarrollo Regional-FEDER. JCF-G was supported by a research contract from the Servicio Andaluz de Salud (SAS) (B-0003-2017). A.M-G. and O.C. are the recipient of a postdoctoral grant (Juan Rodes JR 17/00023 and JR 17/00022, respectively) from the Spanish Ministry of Economy and Competitiveness. None of the funding sources took part in the design, collection, analysis, or interpretation of the data or in the decision to submit the manuscript for publication.

Data Sharing Statement. The dataset (including data dictionaries) of PREDIMED-Plus is available to external investigators in order to make possible the replication of the main analyses used for the published article. However, due to the restrictions imposed by the Informed Consent and the Institutional Review Boards (IRB), bona fide investigators interested in analyzing the PREDIMED-Plus dataset may submit a brief proposal and statistical analysis plan to both corresponding authors. Upon approval from the Steering Committee and IRBs, the data will be made available to them using an onsite secure access data enclave. 


\section{References}

1. Gomez-Huelgas R, Bernal-López MR, Villalobos A, Mancera-Romero J, BacaOsorio AJ, Jansen S, Guijarro R, Salgado F, Tinahones FJ, Serrano-Ríos M. Hypertriglyceridemic waist: an alternative to the metabolic syndrome? Results of the IMAP Study (multidisciplinary intervention in primary care). Int J Obes (Lond). 2011;35(2):292-9

2. Guattini V, Piovesan C, Wittke E, Marcadenti A. Hypertriglyceridemic waist (EWET), glycidic and lipid profile in patients with newly diagnosed heart attack. Nutr Hosp. 2015;32(3):1004-8

3. Lemieux I, Pascot A, Couillard C, Lamarche B, Tchernof A, Alméras N, Després JP. Hypertriglyceridemic waist: A marker of the atherogenic metabolic triad (hyperinsulinemia; hyperapolipoprotein B; small, dense LDL) in men? Circulation 2000; 102(2):179-84

4. Braz MAD, Vieira JN, Gomes FO, da Silva PR, Santos OTM, da Rocha IMG, de Sousa IM, Fayh APT. Hypertriglyceridemic waist phenotype in primary health care: comparison of two cutoff points. Diabetes Metab Syndr Obes. 2017; $10: 385-91$

5. Arsenault BJ, Lemieux I, Després JP, Wareham NJ, Kastelein JJ, Khaw KT, Boekholdt SM. The hypertriglyceridemic waist phenotype and the risk of coronary artery disease: results from the EPIC-Norfolk Prospective Population Study. CMAJ. 2010;182(13):1427-32

6. Haack RL, Horta BL, Gigante DP, Barros FC, Oliveira I, Silveira VM. The hypertriglyceridemic waist phenotype in young adults from the Southern Region of Brazil. Cad Saude Publica 2013; 29(5):999-1007

7. Bach-Faig A, Berry EM, Lairon D, Reguant J, Trichopoulou A, Dernini S, Medina FX, Battino M, Belahsen R, Miranda G, Serra-Majem L; Mediterranean Diet Foundation Expert Group. Mediterranean diet pyramid today. Science and cultural updates. Public Health Nutr. 2011;14(12A):2274-84

8. Martínez-González MA, Gea A, Ruiz-Canela M. The Mediterranean Diet and Cardiovascular Health. Circ Res. 2019;124(5):779-798

9. Maki KC, Beiseigel JM, Jonnalagadda SS, Gugger CK, Reeves MS, Farmer MV, Kaden VN, Rains TM. Whole-grain ready to eat oat cereal, as part of a dietary program for weight loss, reduces low-density lipoprotein cholesterol in adults with overweight and obesity more than a dietary program including lowfiber control foods. J Am Diet Assoc. 2010;110(2):205-14

10. Estruch R, Ros E, Salas-Salvadó J, Covas MI, Corella D, Arós F, GómezGracia E, Ruiz-Gutiérrez V, Fiol M, Lapetra J, Lamuela-Raventos RM, Serra- 
Majem L, Pintó X, Basora J, Muñoz MA, Sorlí JV, Martínez JA, MartínezGonzález MA; PREDIMED Study Investigators. Primary prevention of cardiovascular disease with a Mediterranean diet. N Engl J Med. 2013 Apr 4;368(14):1279-90. Retraction and Republication: Primary Prevention of Cardiovascular Disease with a Mediterranean Diet. N Engl J Med 2013;368:1279-90. N Engl J Med. 2018;378(25):2441-2442

11. Guasch-Ferré M, Salas-Salvadó J, Ros E, Estruch R, Corella D, Fitó M, Martínez-González MA; PREDIMED Investigators. The PREDIMED trial, Mediterranean diet and health outcomes: How strong is the evidence? Nutr Metab Cardiovasc Dis. 2017;27(7):624-632

12. Martínez-González MA, Salas-Salvadó J, Estruch R, Corella D, Fitó M, Ros E; PREDIMED INVESTIGATORS. Benefits of the Mediterranean Diet: Insights From the PREDIMED Study. Prog Cardiovasc Dis. 2015;58(1):50-60

13. Cárdenas Fuentes G, Bawaked RA, Martínez González MÁ, Corella D, Subirana Cachinero I, Salas-Salvadó J, Estruch R, Serra-Majem L, Ros E, Lapetra Peralta J, Fiol M, Rekondo J, Gómez-Gracia E, Tur Marí JA, Pinto Sala X, Babio N, Ortega C, Martínez JA, Schröder H. Association of physical activity with body mass index, waist circumference and incidence of obesity in older adults. Eur J Public Health. 2018; 28(5):944-950

14. Tuomilehto J, Lindström J, Eriksson JG, Valle TT, Hämäläinen $H$, llanneParikka $P$, Keinänen-Kiukaanniemi $S$, Laakso $M$, Louheranta $A$, Rastas $M$, Salminen V, Uusitupa M; Finnish Diabetes Prevention Study Group. Prevention of type 2 diabetes mellitus by changes in lifestyle among subjects with impaired glucose tolerance. N Engl J Med. 2001;344 (18):1343-50

15. Martínez-González MA, Buil-Cosiales P, Corella D, Bulló M, Fitó M, Vioque J, Romaguera D, Martínez JA, Wärnberg J, López-Miranda J, Estruch R, BuenoCavanillas A, Arós F, Tur JA, Tinahones F, Serra-Majem L, Martín V, Lapetra J, Vázquez C, Pintó X, Vidal J, Daimiel L, Delgado-Rodríguez M, Matía P, Ros E, Fernández-Aranda F, Botella C, Portillo MP, Lamuela-Raventós RM, Marcos A, Sáez G, Gómez-Gracia E, Ruiz-Canela M, Toledo E, Alvarez-Alvarez I, DíezEspino J, Sorlí JV, Basora J, Castañer O, Schröder H, Navarrete-Muñoz EM, Zulet MA, García-Rios A, Salas-Salvadó J; PREDIMED-Plus Investigators. Cohort Profile: Design and methods of the PREDIMED-Plus randomized trial. Int J Epidemiol. 2018 Nov 22. doi: 10.1093/ije/dyy225

16. Alberti KG, Eckel RH, Grundy SM, Zimmet PZ, Cleeman JI, Donato KA, Fruchart JC, James WP, Loria CM, Smith SC Jr; International Diabetes Federation Task Force on Epidemiology and Prevention; Hational Heart, Lung, 
and Blood Institute; American Heart Association; World Heart Federation; International Atherosclerosis Society; International Association for the Study of Obesity. Harmonizing the metabolic syndrome: a joint interim statement of the International Diabetes Federation Task Force on Epidemiology and Prevention; National Heart, Lung, and Blood Institute; American Heart Association; World Heart Federation; International. Circulation. 2009;120(16):1640-5

17. World Health Organization. Obesity: Preventing and Managing the Global Epidemic: Report on a WHO Consultation (WHO Technical Report Series 894). World Health Organization: Geneva, Switzerland, 2000

18. Grundy SM, Brewer HB, Cleeman JI, Smith SC, Lenfant C, For the Conference Participants. Definition of metabolic syndrome. Report of the National Heart, Lung, and Blood Institute/American Heart Association Conference on Scientific Issues Related to Definition. Circulation 2004; 109: 433-438

19. Alberti KG, Zimmet P, Shaw J, IDF Epidemiology Task Force Consensus Group. The metabolic syndrome a new worldwide definition. Lancet 2005; 366: 1059-1062

20. Fernandez-Ballart JD, Pinol JL, Zazpe I, Corella D, Carrasco P, Toledo E, Perez-Bauer M, Martínez-Gonzalez MA, Salas-Salvado J, Martín-Moreno JM. Relative validity of a semi-quantitative food-frequency questionnaire in an elderly Mediterranean population of Spain. Br J Nutr. 2009;103(12):1808-16

21. De la Fuente-Arrillaga C, Vazquez Z, Bes-Rastrollo M, Sampson L, MartınezGonzalez, MA. Reproducibility of a Food Frequency Questionnaire (FFQ) Validated in Spain. Public Health Nutr. 2010;13(9):1364-72

22. Rosique-Esteban N, Díaz-López A, Martínez-González MA, Corella D, Goday A, Martínez JA, Romaguera D, Vioque J, Arós F, Garcia-Rios A, Tinahones F, Estruch R, Fernández-García JC, Lapetra J, Serra-Majem L, Pinto X, Tur JA, Bueno-Cavanillas A, Vidal J, Delgado-Rodríguez $M$, Daimiel L, Vázquez $C$, Rubio MÁ, Ros E, Salas-Salvadó J; PREDIMED-PLUS investigators. Leisuretime physical activity, sedentary behaviors, sleep, and cardiometabolic risk factors at baseline in the PREDIMED-PLUS intervention trial: A cross-sectional analysis. PLoS One. 2017;12(3):e0172253

23. Molina L, Sarmiento M, Peñafiel J, Donaire D, Garcia-Aymerich J, Gomez M, Ble M, Ruiz S, Frances A, Schröder H, Marrugat J, Elosua R. Validation of the Regicor Short Physical Activity Questionnaire for the Adult Population. PLoS One. 2017;12(1):e0168148.

24. Tojal L, Alonso-Gómez A, Alberich S, Wärnberg J, Sorto C, Portillo MP, Schröder H, Salas-Salvadó J, Arós F. Association Between Maximal 
Oxygen Consumption and Physical Activity and Sedentary Lifestyle in Metabolic Syndrome. Usefulness of Questionnaires. Rev Esp Cardiol (Engl Ed). 2018 Nov 24. pii: S1885-5857(18)30441-9

25. Topolski TD, LoGerfo J, Patrick DL, Williams B, Walwick J, Patrick MB. The rapid assessment of physical activity (RAPA) among older adults. Prev Chronic Dis 2006;3:A118.

26. Prospective Studies Collaboration and Asia Pacific Cohort Studies Collaboration. Sex-specific relevance of diabetes to occlusive vascular and other mortality: a collaborative meta-analysis of individual data from 980793 adults from 68 prospective studies. Lancet Diabetes Endocrinol.

2018;6(7):538-546; Sattar N. Gender aspects in type 2 diabetes mellitus and cardiometabolic risk. Best Pract Res Clin Endocrinol Metab. 2013;27(4):501-507

27. Freitas RS, Fonseca MJMD, Schmidt MI, Molina MDCB, Almeida MDCC. Hypertriglyceridemic waist phenotype: associated factors and comparison with other cardiovascular and metabolic risk indicators in the ELSA-Brasil study. Cad Saude Publica. 2018;34(4):e00067617

28. Andrade JR, Velasquez-Melendez G, Barreto SM, Pereira TSS, Mill JG, Molina MDCB. Hypertriglyceridemic waist phenotype and nutritional factors: a study with participants of ELSA-Brasil. Rev Bras Epidemiol. 2017;20(3):382-393

29. García Álvarez A1, Serra-Majem L, Castell C, Ribas-Barba L, Méndez MA. Trends in the association between smoking history and general/central obesity in Catalonia, Spain (1992-2003). Nutr Hosp. 2017;34(1):102-110

30. Seravalle G, Grassi G. Obesity and hypertension. Pharmacol Res. 2017; $122: 1-7$

31. Jordan J, Yumuk V, Schlaich M, Nilsson PM, Zahorska-Markiewicz B, Grassi G, Schmieder RE, Engeli S, Finer N. Joint statement of the European Association for the Study of Obesity and the European Society of Hypertension: obesity and difficult to treat arterial hypertension. J Hypertens. 2012;30:1047-1055

32. Fagundes LC, Fernandes MH, Brito TA, Coqueiro RDS, Carneiro JAO. Prevalence and factors associated with hypertriglyceridemic waist in the elderly: a population-based study. Cien Saude Colet. 2018;23(2):607-616

33. Martínez-González MA, Salas-Salvadó J, Estruch R, Corella D, Fitó M, Ros E. Benefits of the Mediterranean Diet: Insights from the PREDIMED Study. Prog Cardiovasc Dis. 2015; 58: 50-60 
34. Dinu M, Pagliai G, Casini A, Sofi F. Mediterranean diet and multiple health outcomes: An umbrella review of meta-analyses of observational studies and randomised trials. Eur J Clin Nutr. 2018; 72: 30-43

35. Andrade JR, Velasquez-Melendez G, Barreto SM, Pereira TSS, Mill JG, Molina MDCB. Hypertriglyceridemic waist phenotype and nutritional factors: a study with participants of ELSA-Brasil. Rev Bras Epidemiol. 2017;20(3):382-393

36. Catapano AL, Graham I, De Backer G, Wiklund O, Chapman MJ, Drexel H, Hoes AW, Jennings CS, Landmesser U, Pedersen TR, Reiner Ž, Riccardi G, Taskinen MR, Tokgozoglu L, Verschuren WMM, Vlachopoulos C, Wood DA, Zamorano JL, Cooney MT; ESC Scientific Document Group. 2016 ESC/EAS guidelines for the management of dyslipidaemias. Eur Heart J. 2016;37 (39):2999-3058

37. Rees K, Takeda A, Martin N, Ellis L, Wijesekara D, Vepa A, Das A, Hartley L, Stranges $S$. Mediterranean-style diet for the primary and secondary prevention of cardiovascular disease. Cochrane Database Syst Rev. 2019;3:CD009825

38. Salas-Salvadó J, Díaz-López A, Ruiz-Canela M, Basora J, Fitó M, Corella D, Serra-Majem L, Wärnberg J, Romaguera D, Estruch R, Vidal J, Martínez JA, Arós F, Vázquez C, Ros E, Vioque J, López-Miranda J, BuenoCavanillas A, Tur JA, Tinahones FJ, Martín V, Lapetra J, Pintó X, Daimiel L, Delgado-Rodríguez M, Matía P, Gómez-Gracia E, Díez-Espino J, Babio N, Castañer O, Sorlí JV, Fiol M, Zulet MÁ, Bulló M, Goday A, MartínezGonzález MÁ; PREDIMED-Plus investigators. Effect of a lifestyle intervention program with energy-restricted Mediterranean diet and exercise on weight loss and cardiovascular risk factors: One-year results of the PREDIMED-Plus Trial. Diabetes Care. 2019;42(5):777-788

39. Sofi F, Dinu M, Pagliai G, Cesari F, Gori AM, Sereni A, Becatti M, Fiorillo C, Marcucci R, Casini A. Low-calorie vegetarian versus Mediterranean diets for reducing body weight and improving cardiovascular risk profile: CARDIVEG Study. Circulation. 2018;137(11):1103-1113

40. Czernichow S, Bruckert E, Bertrais S, Galan P, Hercberg S, Oppert JM. Hypertriglyceridemic waist and 7.5-year prospective risk of cardiovascular disease in asymptomatic middle-aged men. Int J Obes (Lond) 2007;31:791-796

41. Irving BA, Davis CK, Brock DW, Weltman JY, Swift D, Barrett EJ, Gaesser GA, Weltman A. The metabolic syndrome, hypertriglyceridemic waist, and cardiometabolic risk factor profile in obese women. Obe Metab. 2007;3(2):50-57 
42. Vissers D, Hens W, Taeymans J, Baeyens JP, Poortmans J, Van GL. The effect of exercise on visceral adipose tissue in overweight adults: a systematic review and meta-analysis. PLoS One.2013;8(2):e56415

43. Dahl-Petersen IK1, Brage S, Bjerregaard P, Tolstrup JS, Jørgensen ME Physical Activity and Abdominal Fat Distribution in Greenland. Med Sci Sports Exerc. 2017;49(10):2064-2070

44. Churilla JR, Fitzhugh EC. Total physical activity volume, physical activity intensity, and metabolic syndrome: 1999-2004 National Health and Nutrition Examination Survey. Metab Syndr Relat Disord. 2012;10(1):70-6

45. Whitaker KM, Pereira MA, Jacobs DR Jr, Sidney S, Odegaard AO. Sedentary Behavior, Physical Activity, and Abdominal Adipose Tissue Deposition. Med Sci Sports Exerc. 2017;49(3):450-458 
Table 1. Clinical and biochemical differences between individuals with and without hypertriglyceridemic waist (HTGW)

\begin{tabular}{|c|c|c|c|}
\hline & HTGW + & HTGW - & p \\
\hline $\mathbf{N}(\%)$ & $2574(38.2)$ & $4158(61.8)$ & $<0.0001$ \\
\hline Age (years) & $64.6 \pm 4.9$ & $65.1 \pm 4.9$ & $<0.0001$ \\
\hline Sex (Male / Female) (n (\%)) & 1335 (38.3) / 1239 (38.2) & $2153(61.7) / 2005$ (61.8) & $<0.0001 /<0.0001$ \\
\hline Waist circumference (cm) & $109.5 \pm 9.3$ & $107.2 \pm 9.8$ & $<0.0001$ \\
\hline BMI $\left(\mathrm{kg} / \mathrm{m}^{2}\right)$ & $33.1 \pm 3.4$ & $32.5 \pm 3.5$ & $<0.0001$ \\
\hline Overweight (n (\%)) & $504(19.6)$ & $1167(28.1)$ & $<0.0001$ \\
\hline Obesity (n (\%)) & $2070(80.4)$ & 2991 (71.9) & $<0.0001$ \\
\hline SBP $(\mathrm{mmHg})$ & $137 \pm 18$ & $136 \pm 20$ & 0.31 \\
\hline $\mathrm{DBP}(\mathrm{mmHg})$ & $84 \pm 9$ & $84 \pm 10$ & 0.01 \\
\hline Low education level (\%) & $1221(47.4)$ & $1997(48.0)$ & $<0.0001$ \\
\hline Sedentary lifestyle (\%) & 16.5 & 15.0 & $<0.0001$ \\
\hline Smoking (\%) & $376(14.6)$ & $471(11.3)$ & 0.001 \\
\hline Glucose (mg/dL) & $117.2 \pm 34.2$ & $111.0 \pm 25.4$ & $p<0.0001$ \\
\hline HbA1c (\%) & $6.2 \pm 1.0$ & $6.0 \pm 0.8$ & $p<0.0001$ \\
\hline Creatinine (mg/dL) & $0.9 \pm 0.2$ & $0.8 \pm 0.2$ & $\mathrm{p}<0.0001$ \\
\hline Uric acid (mg/dL) & $5.9 \pm 1.4$ & $6.1 \pm 1.5$ & $p<0.0001$ \\
\hline Total cholesterol (mg/dL) & $205.8 \pm 28.9$ & $191.8 \pm 35.9$ & $p<0.0001$ \\
\hline LDLc (mg/dL) & $121.8 \pm 35.5$ & $119.8 \pm 31.3$ & $p<0.0001$ \\
\hline HDLc (mg/dL) & $44.5 \pm 10.3$ & $50.2 \pm 12.2$ & $p<0.0001$ \\
\hline Triglycerides (mg/dL) & $191.0[167.0-236.0]$ & $110.0[89.0-131.0]$ & $p<0.0001$ \\
\hline Lipid-lowering treatment (\%) & 51.6 & 49.4 & $p<0.0001$ \\
\hline Hypertension (\%) & 81.6 & 84.1 & $p<0.0001$ \\
\hline Type 2 diabetes mellitus (\%) & 28.5 & 26.0 & $p<0.0001$ \\
\hline
\end{tabular}

BMI: body mass index. SBP: systolic blood pressure. DBP: diastolic blood pressure. 
Table 2. Energy and food intake (A) and adherence to the MedDiet (B) in individuals with and without hypertriglyceridemic waist (HTGW).

A.

\begin{tabular}{|l|c|c|c|}
\cline { 2 - 4 } \multicolumn{1}{c|}{} & HTGW + & HTGW - & p \\
\hline N (\%) & $2534(38.2)$ & $4108(61.8)$ & $<0.0001$ \\
\hline Energy (kcal) & $2415.1 \pm 636.5$ & $2403.2 \pm 623.4$ & 0.45 \\
\hline Total carbohydrates (g/d) & $245.9 \pm 80.4$ & $249.3 \pm 82.0$ & 0.98 \\
\hline Total protein (g/d) & $98.0 \pm 23.9$ & $97.7 \pm 23.8$ & 0.64 \\
\hline Total fat (g/d) & $105.6 \pm 31.6$ & $97.7 \pm 23.8$ & 0.68 \\
\hline SFA (g/d) & $26.7 \pm 9.7$ & $26.6 \pm 9.6$ & 0.60 \\
\hline MUFA (g/d) & $54.6 \pm 17.5$ & $54.3 \pm 17.2$ & 0.40 \\
\hline PUFA (g/d) & $17.1 \pm 6.8$ & $17.0 \pm 6.9$ & 0.66 \\
\hline Cholesterol (mg/d) & $385.7 \pm 129.1$ & $379.8 \pm 120.6$ & 0.06 \\
\hline Fiber (g/d) & $26.4 \pm 9.2$ & $26.0 \pm 9.1$ & 0.08 \\
\hline Phytosterols (mg/d) & $398.1 \pm 111.2$ & $397.7 \pm 111.4$ & 0.88 \\
\hline Alcohol (g/d) & $11.1 \pm 14.8$ & $11.4 \pm 16.3$ & 0.37 \\
\hline N (\%) & $2574(38.2)$ & $4158(61.8)$ & $<0.0001$ \\
\hline Adherence to MedDiet & $8.3 \pm 2.7$ & $8.6 \pm 2.7$ & $<0.0001$ \\
\hline
\end{tabular}

B.

\begin{tabular}{|l|c|c|c|}
\cline { 2 - 4 } \multicolumn{1}{c|}{} & HTGW + & HTGW - & p \\
\hline $\mathbf{N}(\%)$ & $2574(38.2)$ & $4158(61.8)$ & $<0.0001$ \\
\hline Adherence to MedDiet & $8.3 \pm 2.7$ & $8.6 \pm 2.7$ & $<0.0001$ \\
\hline
\end{tabular}


Table 3. Energy expenditure measured using Minnesota questionnaire between individuals with and without hypertriglyceridemic waist (HTGW).

\begin{tabular}{|l|c|c|c|}
\cline { 2 - 4 } \multicolumn{1}{c|}{} & HTGW + & HTGW - & p \\
\hline N (\%) & $2574(38.2)$ & $4158(61.8)$ & $<0.0001$ \\
\hline Light (Met.min/w) & $1074.3 \pm 988.7$ & $1069.3 \pm 971.5$ & 0.86 \\
\hline Moderate (Met.min/w) & $1576.4 \pm 1570.2$ & $1741.2 \pm 1772.0$ & 0.004 \\
\hline Vigorous (Met.min/ w) & $1048.7 \pm 1547.4$ & $1212.1 \pm 1806.4$ & 0.002 \\
\hline Total (Met.min/w) & $2421.9 \pm 2188.3$ & $2730.2 \pm 2479.6$ & $<0.0001$ \\
\hline
\end{tabular}


Table 4. Simple linear correlations between levels of TGs and WC and different basal characteristics, adherence to MedDiet, and PA for HTGW+ and HTGWsubjects. p-values were determined using Pearson's correlation coefficient.

\begin{tabular}{|c|c|c|c|c|c|c|c|c|}
\hline & \multicolumn{4}{|c|}{ HTGW+ } & \multicolumn{4}{|c|}{ HTGW- } \\
\hline & \multicolumn{2}{|c|}{ TGs } & \multicolumn{2}{|c|}{ wC } & \multicolumn{2}{|c|}{ TGs } & \multicolumn{2}{|c|}{ WC } \\
\hline & $\mathbf{r}$ & $\mathbf{p}$ & $\mathbf{r}$ & $\mathbf{p}$ & $\mathbf{r}$ & $\mathbf{p}$ & $\mathbf{r}$ & $\mathbf{p}$ \\
\hline Age (y) & -0.116 & $<0.0001$ & -0.147 & $<0.0001$ & -0.090 & $<0.0001$ & -0.074 & $<0.0001$ \\
\hline BMI $\left(\mathrm{kg} / \mathrm{m}^{2}\right)$ & 0.003 & 0.86 & 0.666 & $<0.0001$ & -0.096 & $<0.0001$ & 0.665 & $<0.0001$ \\
\hline Tobacco use (yes vs. no) & 0.074 & $<0.0001$ & 0.067 & 0.001 & 0.049 & 0.002 & 0.032 & 0.04 \\
\hline Presence of CVD & 0.003 & 0.87 & 0.078 & $<0.0001$ & -0.053 & 0.001 & 0.041 & 0.008 \\
\hline Presence of DM & 0.049 & 0.01 & 0.087 & $<0.0001$ & -0.009 & 0.59 & 0.076 & $<0.0001$ \\
\hline Educational Level & -0.033 & 0.10 & -0.095 & $<0.0001$ & -0.033 & 0.04 & -0.040 & 0.01 \\
\hline Glucose (mg/dL) & 0.092 & $<0.0001$ & 0.132 & $<0.0001$ & -0.015 & 0.35 & 0.150 & $<0.0001$ \\
\hline HbA1c (\%) & 0.077 & $<0.0001$ & 0.110 & $<0.0001$ & -0.017 & 0.31 & 0.114 & $<0.0001$ \\
\hline Creatinine $(\mathrm{mg} / \mathrm{dL})$ & 0.134 & $<0.0001$ & 0.262 & $<0.0001$ & 0.106 & $<0.0001$ & 0.134 & $<0.0001$ \\
\hline Total cholesterol (mg/dL) & -0.001 & 0.94 & -0.148 & $<0.0001$ & 0.018 & 0.27 & -0.168 & $<0.0001$ \\
\hline LDLc (mg/dL) & 0.034 & 0.10 & -0.045 & 0.028 & 0.035 & 0.03 & -0.051 & 0.001 \\
\hline VLDLc (mg/dL) & 0.379 & $<0.0001$ & 0.080 & $<0.0001$ & 0.455 & $<0.0001$ & -0.096 & $<0.0001$ \\
\hline HDLc (mg/dL) & -0.208 & $<0.0001$ & -0.191 & $<0.0001$ & -0.200 & $<0.0001$ & -0.174 & $<0.0001$ \\
\hline Adherence to MedDiet (p17) & -0.026 & 0.20 & -0.136 & $<0.0001$ & -0.060 & $<0.0001$ & -0.098 & $<0.0001$ \\
\hline Sedentarism & 0.036 & 0.08 & 0.062 & 0.002 & 0.007 & 0.70 & 0.093 & $<0.0001$ \\
\hline Moderate PA (Met.min/d) & -0.012 & 0.56 & -0.010 & 0.61 & -0.005 & 0.75 & -0.017 & 0.26 \\
\hline Vigorous PA (Met.min/d) & -0.046 & 0.02 & -0.071 & $<0.0001$ & -0.005 & 0.77 & -0.043 & 0.005 \\
\hline Total PA (Met.min/d) & -0.036 & 0.07 & 0.047 & 0.02 & -0.008 & 0.64 & -0.038 & 0.01 \\
\hline
\end{tabular}


Table 5. Factors associated with the presence of hypertriglyceridemic waist. (HTGW+ vs HTGW-). Multivariate analysis.

\begin{tabular}{|l|c|c|}
\cline { 2 - 3 } \multicolumn{1}{c|}{} & OR (95\% Cl) & p \\
\hline Sex (Female vs. Male) & $1.05(0.94-1.17)$ & 0.36 \\
\hline Age (y) & $0.98(0.97-0.99)$ & 0.002 \\
\hline BMI (kg/m ${ }^{2}$ ) & $1.05(1.03-1.07)$ & $<0.0001$ \\
\hline Smoking (yes vs. no) & $1.29(1.11-1.50)$ & 0.01 \\
\hline Low education level (yes vs. no) & $0.99(0.89-1.10)$ & 0.85 \\
\hline Adherence to MedDiet (p17) & $0.96(0.95-0.98)$ & $<0.0001$ \\
\hline Sedentarism (yes vs. no) & $0.97(0.85-1.12)$ & 0.73 \\
\hline Total energy expenditure (Met.min/d) & $0.995(0.994-0.996)$ & 0.002 \\
\hline Hypertension (yes vs. no) & $0.84(0.73-0.96)$ & 0.01 \\
\hline T2DM (yes vs. no) & $1.13(1.01-1.26)$ & 0.03 \\
\hline
\end{tabular}

